\title{
CHILD-TURCOTTE-PUGH /ALBUMINURIA AS A PREDICTOR OF ACUTE KIDNEY INJURY AMONG HOSPITALIZED PATIENTS WITH LIVER CIRRHOSIS
}

\author{
By \\ Othman Mohammed Ahmed Othman*, Mohammad Sad Al-Den \\ Radwan**, Sadek Mostafa Sadek* and Ashraf Mohammed El-Bahrawy* \\ Departments of *Internal Medicine and **Clinical Pathology, Faculty of Medicine, Al- \\ Azhar University \\ Corresponding author: Othman Mohammed Ahmed Othman \\ E-mail: doctorosmanmahmedosman@gmail.com
}

\begin{abstract}
Background: The incidence of acute kidney injury (AKI) in cirrhotic patients about fifteen percent of hospitalized cirrhotic patient, Prediction of AKI indicated in all patients with liver cirrhosis. Albuminuria in cirrhotic patient can predict AKI.
\end{abstract}

Objective: To assess the role of Child-Turcotte Pugh/Albuminuria (CTP-Alb), in prediction of AKI among hospitalized patients with liver cirrhosis.

Patients and Methods: After departmental ethics committee approval and patient consents were obtained, 60 patients with liver cirrhosis screened for AKI during hospital admission at hepatogastroenterology unit, Department of Internal Medicine in Al-Hussein Hospital, Al-Azhar University, and The study was carried out during the period from September 2019 and September 2020, The diagnosis of liver cirrhosis based on clinical, biochemical and ultrasonography findings. Patients with Fib-4 $\geq 3.5$ in the absence of liver decomposition were categorized as compensated liver cirrhosis. Severity of liver disease was assessed using the CTP score, model for end stage liver disease (MELD) score and CTP-Alb score. Diagnosis of acute kidney injury was based on the changes in serum creatinine. The baseline renal assessment at first day of hospital admission was included serum creatinine, estimated glomerular filtration rate (eGFR), albumin/creatinine ratio, and abdominal ultrasonography. AKI was categorized as hepatorenal syndrome (HRS), pre-renal azotemia, post-renal azotemia or intrinsic acute kidney injury.

Results: A total of 60 patients included. They were $40(66.66 \%)$ males and $20(33.34 \%)$ females. Their mean age was $50 \pm 33$ years, of them $8(13.33 \%)$ patients developed AKI during hospital admission with their mean age was $60.6 \pm 10.9$ years. They were $5(62.5 \%)$ males and $3(37.5 \%)$ females, Hypoalbuminemia, Child score at admission and Child-albuminuria score at admission were identified as independent risk factors for AKI by multivariate analysis ( $\mathrm{p}<0.05$ ).

Conclusion: Thirteen percent of cirrhotic patients developed AKI during hospital admission according to our results. The majority of patients were child C in our series; CTP/Albuminuria score, Hypoalbuminemia and ACLF has promising sensitivity, specificity and accuracy in prediction of AKI in hospitalized cirrhotic patient.

Key words: AKI, CTP/Albuminuria score, Hypoalbuminemia and ACLF. 


\section{INTRODUCTION}

Renal dysfunction is a common complication of liver cirrhosis. This may be related to the abnormal hemodynamics of systemic and splanchnic arterial vasodilation and extra-hepatic vasoconstriction peculiar to advanced cirrhosis (Wong, 2012).

Regardless of the cause, the development of AKI has a profound impact on survival. This is particularly true in those with AKI who then progress to persistent kidney injury, where the 30day mortality rate is nearly 10 -fold higher (Belcher et al., 2013).

The diagnosis of AKI in cirrhosis has undergone dramatic changes in recent years, partly related to better understanding of the pathophysiology of AKI, and partly related to the need to institute earlier treatment, so to improve the prognosis of these patients. The IAC proposed changes in the definition and diagnostic criteria for AKI in cirrhosis is the first step towards better identification of these patients. Once validated, these diagnostic criteria will help to contribute to an improved prognosis of these patients. The use of biomarkers in the future will certainly further enhance the diagnostic accuracy of AKI for the patients (Wong, 2016).

The renal dysfunction is not represented in CTP score. Diagnostic information is contained in the renal function in cirrhotic patients which could add much to the standard CTP score. The addition of serum creatinine to the CTP score did not significantly improve its predictive ability (Amathieu et al., 2017).
The present work aimed to assess the role of Child-Turcotte-Pugh/albuminuria (CTP-Alb), in prediction of AKI among hospitalized patients with liver cirrhosis.

\section{PATIENTS AND METHODS}

This was a cross sectional study conducted on 60 adult patients with liver cirrhosis admitted to hospital. Patients were admitted to the Gastroenterology and Hepatology Unit, Department of Internal Medicine, Al-Azhar University, Cairo, Egypt. Approval of the medical ethics committee of Al-Azhar Faculty of Medicine had been taken. An informed consent from patient or patients' next of kin had been taken before enrollment to the study.

\section{Inclusion criteria:}

Patients with liver cirrhosis aged between (17-83) years included.

\section{Exclusion criteria:}

Severe cardiopulmonary disease, history of renal disease, had previous liver transplantation, nephrotoxic drugs or NSAIDs use in the last 4 weeks or diabetes mellitus.

The diagnosis of decompensated liver cirrhosis based on combination of clinical, biochemical and ultrasonography findings. Patients with Fib- $4 \geq 3.5$ in the absence of liver decomposition were categorized as compensated liver cirrhosis. Severity of liver disease was assessed using the CTP score, MELD score, and CTP-Alb score. Diagnosis of acute kidney injury based on the changes in serum creatinine. The baseline renal assessment at first day of hospital admission included serum creatinine, eGFR, albumin/creatinine ratio, and abdominal ultrasonography. The 
cause of AKI was categorized as HRS, pre-renal azotemia, post-renal azotemia or intrinsic acute kidney injury. The primary study outcome was occurrence of AKI during hospitalization and the secondary outcome was in hospital mortality.

\section{Statistical analysis:}

Data were analyzed using Statistical Pachage for Social Science (SPSS) version 24. Quantitative data were expressed as mean \pm standard deviation (SD) and median. Qualitative data were expressed as frequency and percentage.

Independent-samples t-test of significance was used when comparing between two means (for normal distributed data). Mann-Whitney U test: was used when comparing between two means (for abnormal distributed data). Pvalue $<0.05$ was considered significant.

\section{RESULTS}

Among 60 patients with liver cirrhosis, they were $40(66.66 \%)$ males and 20 (33.34\%) females, their mean age was 50 \pm 33 years, of them 8 (13.33\%) patients developed AKI during hospital admission. their mean age was $60.6 \pm 10.9$ years. They were $5(62.5 \%)$ males and $3(37.5 \%)$ females.
There was a significant relationship between cirrhotic patient with AKI and hypoalbuminemia, as p values were 0.042 , while no significant relationship between cirrhotic patient with AKI and other laboratory parameters (Table 1).

Table (1): Comparisons of laboratory tests as regard AKI

\begin{tabular}{|c|c|c|c|c|}
\hline \multicolumn{2}{|c|}{$\begin{array}{c}\text { AKI } \\
\text { Parameters } \\
\end{array}$} & \multirow{3}{*}{$\begin{array}{c}\begin{array}{c}\text { No } \\
(\mathbf{n}=\mathbf{5 2})\end{array} \\
10.5 \pm 2.4 \\
10.5\end{array}$} & \multirow{3}{*}{$\begin{array}{c}\begin{array}{c}\text { Yes } \\
(\mathbf{n}=\mathbf{8})\end{array} \\
9.2 \pm 1.6 \\
9.4\end{array}$} & \multirow{3}{*}{$\begin{array}{r}\text { P-value } \\
0.162\end{array}$} \\
\hline \multirow{2}{*}{ Hb (g/dl) } & Mean \pm SD & & & \\
\hline & Median & & & \\
\hline \multirow{2}{*}{$\begin{array}{c}\text { PLTs } \\
(\mathbf{x 1 0} / \mathbf{u l})\end{array}$} & Mean \pm SD & $102.6 \pm 70.1$ & $102.1 \pm 45.4$ & \multirow{2}{*}{0.557} \\
\hline & Median & 81 & 86 & \\
\hline \multirow{2}{*}{$\begin{array}{c}\text { TLC } \\
\left(\mathbf{x 1 0}^{3} / \mathrm{ul}\right)\end{array}$} & Mean \pm SD & $6.5 \pm 3.9$ & $6.1 \pm 1.9$ & \multirow{2}{*}{0.777} \\
\hline & Median & 5.8 & 6.5 & \\
\hline \multirow{2}{*}{ AST (U/L) } & Mean \pm SD & $45.3 \pm 32.1$ & $43.3 \pm 21.9$ & \multirow{2}{*}{0.720} \\
\hline & Median & 31.5 & 40.5 & \\
\hline \multirow{2}{*}{ ALT (U/L) } & Mean \pm SD & $28.6 \pm 26.9$ & $21.1 \pm 6.1$ & \multirow{2}{*}{0.819} \\
\hline & Median & 20.5 & 22.5 & \\
\hline \multirow{2}{*}{$\operatorname{ALB}(\mathrm{g} / \mathrm{dl})$} & Mean \pm SD & $3.6 \pm 0.6$ & $3.01 \pm 0.6$ & \multirow{2}{*}{0.042} \\
\hline & Median & 3.6 & 3.3 & \\
\hline \multirow{2}{*}{$\begin{array}{l}\text { T. Bilirubin } \\
\text { (mg/dl) }\end{array}$} & Mean \pm SD & $2.2 \pm 2.8$ & $2.7 \pm 2.8$ & \multirow{2}{*}{0.609} \\
\hline & Median & 1.3 & 1.5 & \\
\hline \multirow{2}{*}{$\begin{array}{l}\text { D. Bilirubin } \\
\text { (mg/dl) }\end{array}$} & Mean \pm SD & $1.08 \pm 2.2$ & $1.45 \pm 1.7$ & \multirow{2}{*}{0.177} \\
\hline & Median & 0.4 & 0.8 & \\
\hline \multirow{2}{*}{ INR } & Mean \pm SD & $1.5 \pm 0.5$ & $1.6 \pm 0.3$ & \multirow{2}{*}{0.071} \\
\hline & Median & 1.3 & 1.6 & \\
\hline
\end{tabular}

Child score at admission, Child-albuminuria score at admission and acute on top of chronic liver failure (ACLF) were identified as independent risk factors for AKI by multivariate analysis $(\mathrm{p}<0.05)$, (Table 2$)$. 
Table (2): Predictors of AKI in hospitalized cirrhotic patients by multivariate analysis

\begin{tabular}{|c|c|c|c|c|c|}
\hline & $\mathbf{B}$ & SE & p-value & \multicolumn{2}{|c|}{$95 \%$ CL } \\
\hline (Constant) & -3.1 & 2 & 0.116 & & \\
\hline Age & 0.02 & 0.033 & 0.509 & 0.95 & 1.08 \\
\hline Sex & 0.21 & 0.78 & 0.789 & 0.26 & 5.8 \\
\hline Abdominal Pain & 1.2 & 0.78 & 0.123 & 0.7 & 15.4 \\
\hline Abdominal Distension & 2.8 & 1.3 & 0.029 & 1.33 & 216.6 \\
\hline Hematemesis & 0.6 & 0.9 & 0.502 & 0.31 & 10.7 \\
\hline Melena & -19.5 & 14210 & 0.999 & ---- & ---- \\
\hline Jaundice & 19.4 & 40192 & 1.0 & ---- & ----- \\
\hline Dyspnea & 19.3 & 23205 & 0.999 & $-\overline{---}$ & ----- \\
\hline Weight loss & 19.4 & 40192 & 1.0 & ---- & ----- \\
\hline Poly-arthralgia & 19.4 & 40192 & 1.0 & ---- & ----- \\
\hline Easy Fatigability & 19.4 & 40192 & 1.0 & ---- & ----- \\
\hline SBP & -0.074 & 0.067 & 0.271 & 0.814 & 1.06 \\
\hline DBP & -0.035 & 0.77 & 0.649 & 0.830 & 1.12 \\
\hline Temp & 0.52 & 0.76 & 0.488 & 0.381 & 7.5 \\
\hline Jaundice (Clinical) & 0.33 & 0.88 & 0.705 & 0.24 & 7.9 \\
\hline Ascites & 1.56 & 0.86 & 0.07 & 0.88 & 26.1 \\
\hline HE & 23.2 & 40192 & 1.0 & ---- & ----- \\
\hline Lower limb Edema & 1.14 & 0.78 & 0.145 & 0.67 & 14.7 \\
\hline HB & -0.23 & 0.17 & 0.167 & 0.56 & 1.1 \\
\hline PLT & 0.0 & 0.006 & 0.986 & 0.98 & 1.01 \\
\hline TLC & -0.02 & 0.112 & 0.803 & 0.78 & 1.2 \\
\hline AST & -0.002 & 0.013 & 0.859 & 0.97 & 1.02 \\
\hline ALT & -0.019 & 0.024 & 0.435 & 0.93 & 1.02 \\
\hline ALB & -1.3 & 0.65 & 0.003 & 0.069 & 0.89 \\
\hline T. Bilirubin & 0.058 & 0.11 & 0.622 & 0.84 & 1.3 \\
\hline D. Bilirubin & 0.069 & 0.15 & 0.644 & 0.79 & 1.43 \\
\hline INR & 0.36 & 0.66 & 0.587 & 0.38 & 5.3 \\
\hline Creat (Basal) & -2.09 & 1.9 & 0.280 & 0.003 & 5.5 \\
\hline HBs Ag & 19.4 & 40192 & 1.0 & ---- & ----- \\
\hline HCV Ag & 19.6 & 11602 & 0.999 & 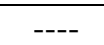 & ----- \\
\hline ALB/Creat ratio & -0.003 & 0.005 & 0.558 & 0.98 & 1.007 \\
\hline \multirow[t]{2}{*}{ Urine Pus } & 1.98 & 1.47 & 0.177 & 0.4 & 130.07 \\
\hline & B & $\mathbf{S E}$ & p-value & \multicolumn{2}{|c|}{$95 \% \mathrm{CL}$} \\
\hline Urine Crystals & 1.27 & 1.29 & 0.324 & 0.28 & 44.7 \\
\hline Paracentesis Pus & 23.2 & 40192 & 1.0 & --- & ---- \\
\hline Plural effusion & 1.7 & 0.86 & 0.049 & 1.005 & 30.3 \\
\hline Splenomegaly & 19.5 & 16408 & 0.999 & ---- & ----- \\
\hline Ascites (US) & 0.7 & 0.86 & 0.412 & 0.37 & 11.05 \\
\hline HFL & 0.3 & 0.79 & 0.704 & 0.28 & 6.3 \\
\hline PVT & -0.085 & 1.14 & 0.914 & 0.098 & 8.6 \\
\hline Nephropathic & -19.3 & 28420 & 0.999 & $-\cdots$ & ----- \\
\hline OV & -19.3 & 28420 & 0.999 & ---- & ----- \\
\hline PHG & -19.3 & 28420 & 0.999 & ---- & $-\cdots--$ \\
\hline CHILD (Admission) & 2.6 & 1.2 & 0.026 & 1.37 & 156.9 \\
\hline CTP & 0.44 & 0.193 & 0.02 & 1.07 & 2.28 \\
\hline MELD (Admission) & 0.09 & 0.061 & 0.138 & 0.97 & 1.23 \\
\hline GFR (Admission) & -0.017 & 0.017 & 0.318 & 0.95 & 1.01 \\
\hline FIB4 Score & -0.041 & 0.069 & 0.552 & 0.83 & 1.09 \\
\hline ACLF & 1.97 & 0.89 & 0.028 & 1.24 & 41.7 \\
\hline
\end{tabular}




\section{DISCUSSION}

The exact mechanisms implicated in the pathogenesis of microalbuminuria in cirrhotic patient remain unclear, liver cirrhosis is considered a systemic disease affecting the function of several extrahepatic organs as a result of bacterial translocation from the gut and the development of hyperdynamic circulation. Thus, patients with liver cirrhosis especially decompensated cirrhosis (DC) have decreased effective arterial blood volume leading to renal hypoperfusion, deterioration of GFR and simultaneous compensatory activation of the endogenous sympathetic system and renal vasoconstrictor systems, such as renin angiotensen aldosterone system (RAAS). In fact, in patients with DC, greater activation of RAAS correlates with the severity of renal dysfunction. Taken together, these all mechanisms may explain the pathogenesis of microalbuminuria in cirrhotic patient, explained by Cholongitas et al. (2014).

In the current study, we found that $13.3 \%$ of cirrhotic patient developed AKI during hospital admission. Hypoalbuminemia, child/Albuminuria score and ACLF at admission were independent predictors of AKI in hospitalized patients with liver cirrhosis. Going with this result albuminuria was significantly higher in cirrhotic patients adjudicated with acute tubular necrosis (ATN) versus non-ATN (Belcher et al., 2014).

In our study, we firstly found that CTP/Albuminuria score can discriminate between patients with AKI and patients without AKI at a cutoff level of >10.5, with $50 \%$ sensitivity, $88.5 \%$ specificity,
81.3\% PPV and $63.9 \%$ NPV. This hints that albuminuria can be predicted early before deterioration of serum creatinine and can segregate cirrhotic patients with risk of AKI.

Moreau et al. (2013) mentioned that the renal dysfunction or failure is universally presented in patients with ACLF, according to the definition by the European association for the study of the liver disease - chronic liver failure (EASLCLIF) consortium. In agreement with this concept in the current study, we demonstrated that the ACLF is independent predictor of AKI in cirrhotic patients.

Mi-yeon et al. (2017) reported that the hypoalbuminemia at admission predicts the development of acute kidney injury in hospitalized patients and replacement of albumin after development of AKI may contribute to renal recovery. In addition, Wiedermann et al. (2010) showed that the lower serum albumin was significant independent predictor of AKI development in chronic liver disease patients.

Going with these results, our findings indicate that Hypoalbuminemia can be used to discriminate between patients with AKI and patients without AKI at a cutoff level of $<3.2$, with $50 \%$ sensitivity, $75 \%$ specificity, 66.7\% PPV and 60\% NPV.

\section{CONCLUSION}

CTP/Albuminuria score, hypoalbuminemia and ACLF have promising sensitivity, specificity and accuracy in prediction of AKI in hospitalized cirrhotic patient. 


\section{OTHMAN MOHAMMED AHMED OTHMAN et al.,}

\section{REFERENCES}

1. Amathieu R, Al-khafaji A, Sileanu FE and Foldes E. (2017): Significance of Oliguria in Critically Ill Patients with Chronic Liver Disease. Hepatology, 66(5):1592-1600.

2. Belcher JM, Garcia-Tsao G, Sanyal AJ, Bhogal H, Lim JK, Ansari N, Coca GS and Parikh CR. (2013): Association of AKI with mortality and complications in hospitalized patients with cirrhosis. Hepatology, 57:753762.

3. Belcher JM, Sanyal AJ, Peixoto AJ, Perazella MA, Lim J, ThiessenPhilbrook H, Ansari N, Coca SG, Garcia-Taso $G$ and Parikh CR. (2014): Kidney biomarkers and differential diagnosis of patients with cirrhosis and acute kidney injury. Hepatology, 60(2):622-32.

4. Cholongitas E, Arsos G, Goulis J, Birtsou C, Haidich AB, Nakouti T, Chalevas P, Ioannidou M, Karakatsanis $K$ and Akriviadis E. (2014): Glomerular filtration rate is an independent factor of mortality in patients with decompensated cirrhosis. Hepatol Res, 44(10):E145-55.

5. Moreau R, Jalan R, Gines P, Pavesi M, Angeli P, Cordoba J, Durand F, Gustot T, Saliba F, Domenicali M, Gerbes A, Wendon J, Alessandria C, Laleman W, Zeuzem S and Arroyo V. (2013): Acute-on-chronic liver failure is a distinct syndrome that develops in patients with acute decompensation of cirrhosis. Gastroenterology,144:1426-1437.

6. Slack AJ, McPhail MJ, Ostermann M, Bruce M, Sherwood R, Musto R, Dew T, Auzinger G, Bernal W, O'Grady J, Heneghan MA, Moore K and Wendon JA. (2013): Predicting the development of acute Kidney injury in liver cirrhosis - an analysis of glomerular filtration rate, proteinuria and kidney injury biomarkers. Aliment Pharmacol Ther., 37: 989-997.

7. Wiedermann CJ, Wiedermann W and Joannidis M. (2010): Hypoalbuminemia and acute kidney injury. Intensive care Med., 36: 16571665.

8. Wong F. (2012): Recent advances in our understanding of hepatorenal syndrome. Nat Rev Gastroenterol Hepatol., 9: 382-391.

9. Wong F. (2016): Acute kidney injury in liver cirrhosis: new definition and application. Clinical and Molecular Hepatology, 22:415-422.

10. Yo M, Lee SW, Baek SH, Na KY, Chae DW, Chin HJ and Kim S. (2017): Hypoalbuminemia at admission predicts the development of AKI in hospitalized patients: a retrospective cohort study. PLOS 12(7), e 0180750. 
دور معامل شبلد مضافا إلبه كمية تسرب الز لال بالبول فى التتبوء بحدوث خلل حاد بوظائف الكلى بين مرضى الثمع

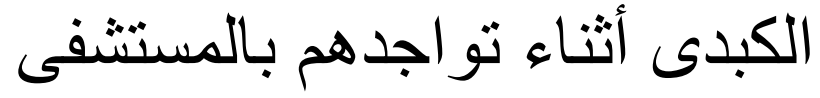

عثمان محمد أحمد عثمان*، محمد سعد الدين رضوان***، صادق مصطفى صادق*، * أشرف محمد البحراوي

قسمي الأمراض الباطنة*، والباثولوجيا الاكلينيكيه**، كلية الطب، جامعة الأزهر

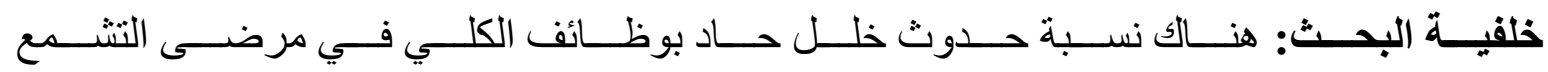

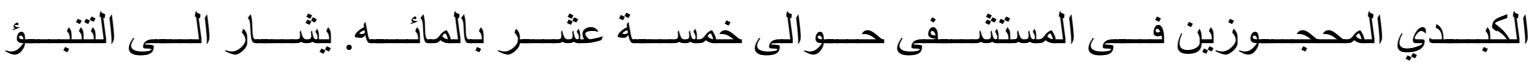

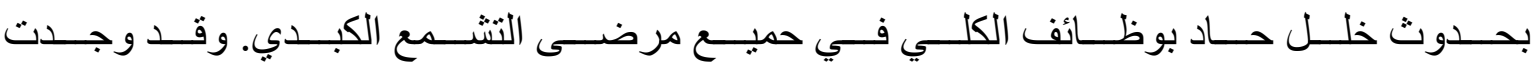

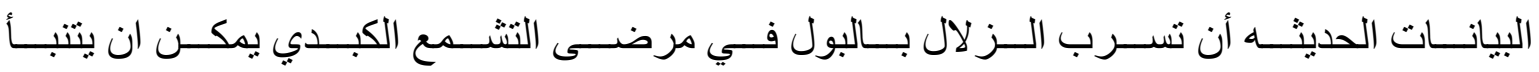
بحدوث خلل حاد بوظائف الكلي.

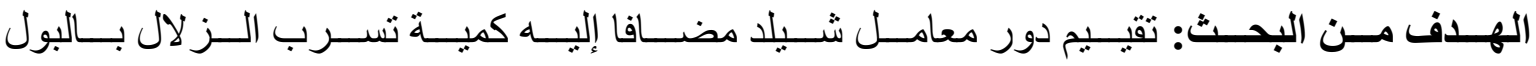

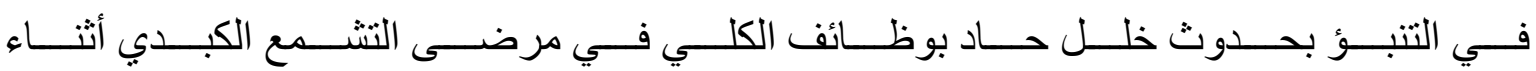
تو اجدهم بالمستشفى.

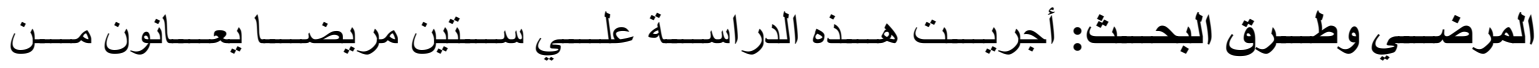

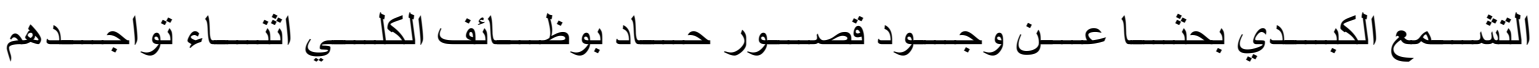

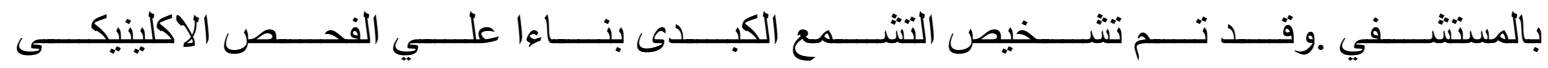

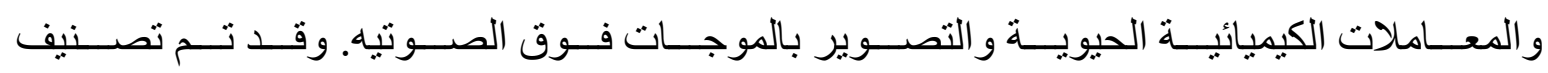

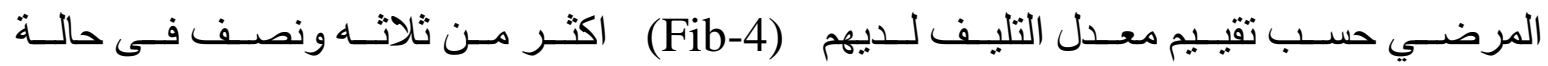

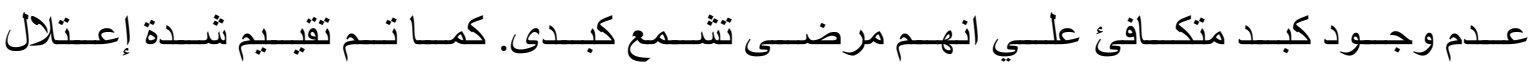

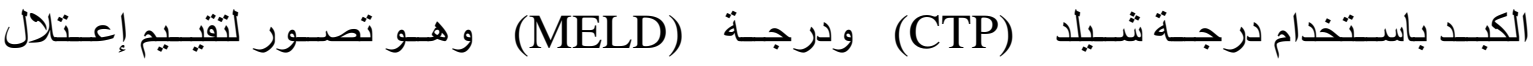
الكبد المتاخر.

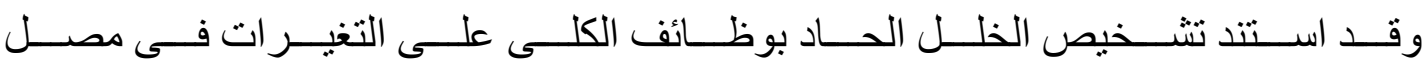

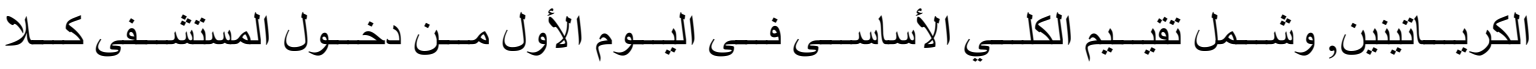

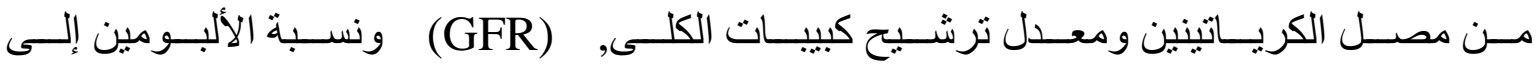

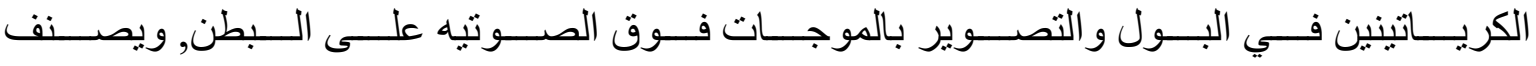




\section{OTHMAN MOHAMMED AHMED OTHMAN et al.,}

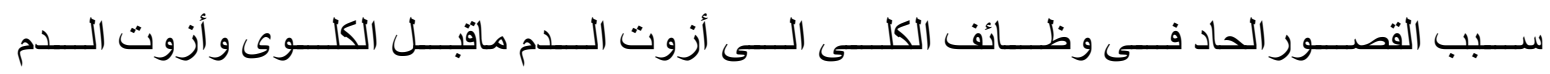
مابعد الكلوى ومتلازمة القصور الكبدى الكلوى و إصابة الكلى الحادة الداخلية.

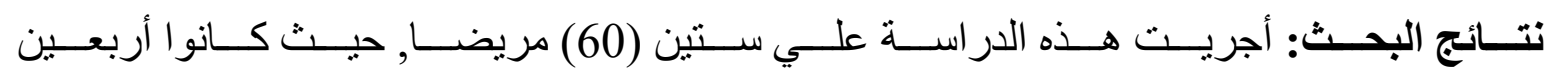

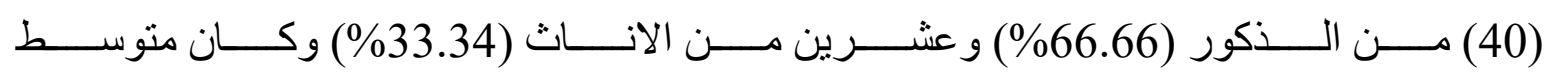

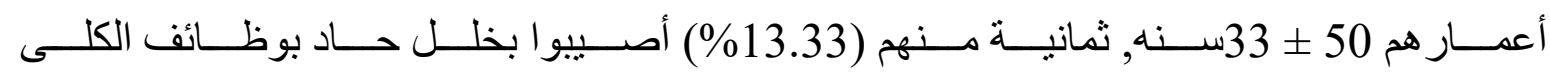

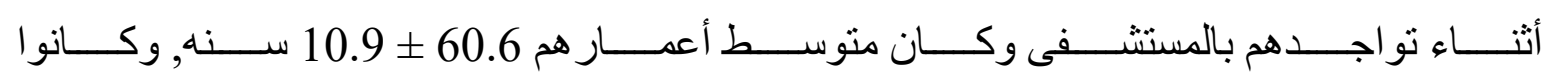
خمسة رجال (62.5\%) وثناث سيدات (157.5\%).

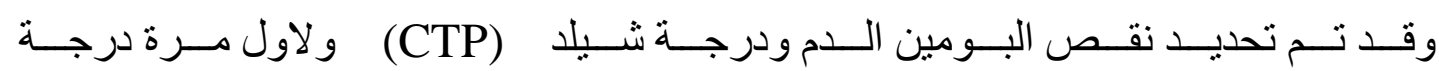

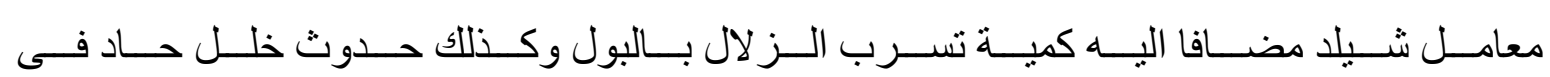

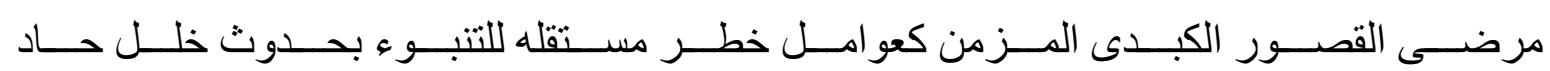
بوظائف الكلي عن طريق التحليل متعدد التغير ات (0.05>0.05).

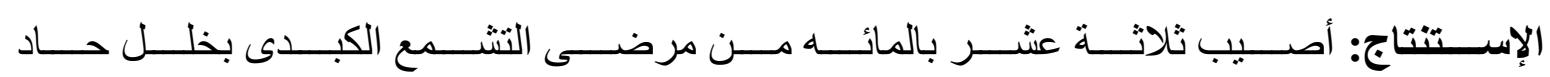

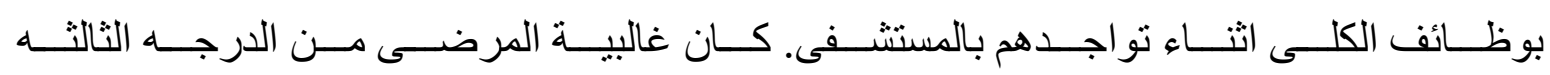

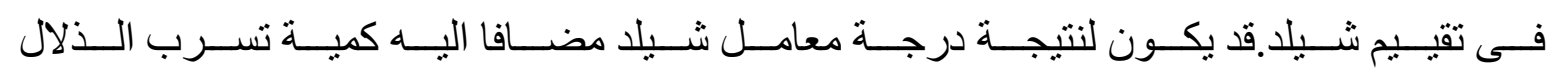

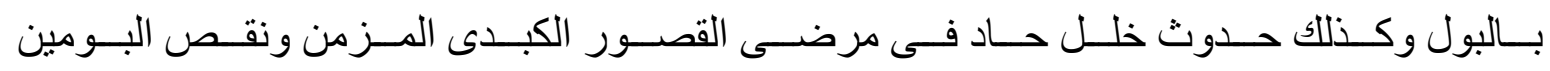

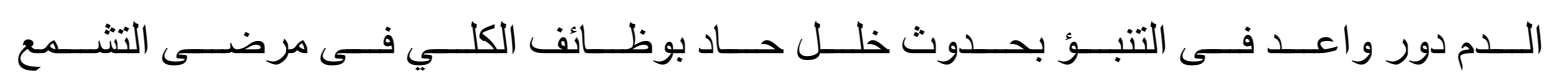
الكبدى اثناء تو اجدهم بالمستثفى. 